\title{
A Mixed Research Investigation of Factors Related to Time to the Doctorate in Education
}

\author{
Hesborn O. Wao \\ Center for Evidence-Based \\ Medicine and Health Outcomes \\ Research, University of South \\ Florida, Tampa, FL, USA
}

\author{
Anthony J. Onwuegbuzie \\ Department of Educational \\ Leadership and Counseling, \\ Sam Houston State University, \\ Huntsville, TX, USA
}

tonyonwuegbuzie@aol.com

Abstract

Students, educators, employers, and other stakeholders are concerned by the continued lengthening of time to attainment of the doctorate (TTD). A sequential quantitative-qualitative mixed research design was utilized in this study to understand what factors influence TTD. In the quantitative phase, discrete-time event history modeling was employed to analyze secondary data on 1,028 Education graduates between 1990 and 2006. The qualitative phase included interviews with students and graduates and focus groups with faculty members. Findings from both phases suggest that factors related to TTD are intertwined and involve a complex interplay of institutional and personal factors. TTD, according to the proposed integrated conceptual scheme of TTD, is influenced by the level of integration in five domains: academic, social, economic, personal, and external factors. Of these domains, academic integration seems to have the greatest connection with TTD, whereby, in the quantitative phase, student-related factors (e.g., master's grade point average [GPA]) and institution-related factors (viz., proportion of female students, the mean graduate record examination [GRE] quantitative score, the size of the department housing the program and, in the qualitative phase, institution-related factors (e.g., how the program is structured, levels of academic preparation, and whether a student is enrolled full-time vs. part-time) were associated with TTD. This is followed by social integration factors, particularly the nature of advising and of dissertation topic chosen by students (qualitative phase). The impact of economic factors including work and financial support is moderate, whereas personal attributes such as the level of motivation and external factors such as family obligations also have some association with TTD (qualitative phase). Limitations and implications are addressed.

Key Words: doctoral persistence, event history modeling, focus groups, frequency/intensity effect size, hierarchical linear modeling, time-to-degree

Material published as part of this publication, either on-line or in print, is copyrighted by the Informing Science Institute. Permission to make digital or paper copy of part or all of these works for personal or classroom use is granted without fee provided that the copies are not made or distributed for profit or commercial advantage AND that copies 1) bear this notice in full and 2) give the full citation on the first page. It is permissible to abstract these works so long as credit is given. To copy in all other cases or to republish or to post on a server or to redistribute to lists requires specific permission and payment of a fee. Contact Publisher@InformingScience.org to request redistribution permission.

\section{Introduction}

Although the attainment of the doctorate is considered to be the pinnacle of education, in the United States, the time taken to attain the doctorate (TTD) has been increasing over the years (Bowen \& Rudenstine, 1992; Hoffer, Hess, Welch, \& Williams, 2007). Indeed, less than one half of all students admitted into doctoral programs attain the docto- 
rate even after pursuing it from 6 to 12 years, with a more pronounced increase in total TTD being witnessed in Education than in any other fields (Bowen \& Rudenstine, 1992). According to the Survey of Earned Doctorates 2006 Report, between 1980 and 2006 the median duration between starting and completing graduate school increased from 10.7 to 12.7 years in Education compared to 7.7 to 7.9 years in all fields including Education (Hoffer et al., 2007). Given the increase in cost incurred in preparing students and the delay in entry into the workforce (Tuckman, Coyle, \& Bae, 1990), students, faculty, employers, and other stakeholders in higher education are concerned when the doctorate is not attained in a timely manner. In response to the concern about the lengthening trend in TTD, several studies have been conducted that examine factors influencing TTD (Bair, 1999; Ferrer de Valero, 2001; Maher, Ford, \& Thompson, 2004; Nerad \& Cerny, 1993; Stolzenberg, 2006).

Although prior studies, including Bair's (1999) meta-synthesis, have emphasized the need to conduct qualitative studies that capture students' thoughts, feelings, and behaviors regarding TTD, to date, only in a few studies have qualitative approaches been employed to examine factors associated with TTD (e.g., Nerad \& Cerny, 1993). Most of these studies have been included as part of quantitative studies, for instance, as a means to facilitate instrument development (e.g., preceding a survey with a focus groups, Maher et al., 2004), as a complement to the quantitative component (e.g., Ferrer de Valero, 2001), or in the form of open-ended items included in a survey (e.g., Stolzenberg, 2006). Extrapolation of qualitative findings, however, has been limited, partly because of the tendency to focus on either student or faculty perspectives but seldom incorporating both views.

In this study, we sought to use mixed research techniques to identify the factors that influence the time that students take to attain the doctorate. Educators would like to know whether the factors are institution-related and are thus out of control of students. Similarly, students would like to know their roles in ensuring timely completion. Student interviews and faculty focus groups allow for investigating opinions and experiences of these constituents regarding factors perceived to influence TTD. Because TTD "varies more systematically with discipline of study than any other variable" (Bowen \& Rudenstine, 1992, p. 123), we chose Education, a field that has continued to experience the longest TTD, to control for the effect of the field.

In Girves and Wemmerus' (1988) model, departmental characteristics, such as the percentage of female students and the percentage of White students, the extent to which students perceive that faculty treat them as colleagues, and the availability of financial support, are related to degree progress. Rather than focusing on characteristics of admitted students, the model emphasizes creating an environment conducive for doctorate attainment. It is consistent with Lovitts's (2001) findings in which institutional factors were observed as exerting more influence on persistence than did student characteristics.

Tinto's (1993) model emphasizes the concept of graduate communities into which students are integrated to become members. He illustrates doctoral persistence as occurring in three stages. In the first stage, students transition and adjust to the social and academic systems of the graduate community. In the second stage, students acquire knowledge and develop competencies necessary for conducting doctoral research. Here, academic integration (e.g., classroom relations) and social integration (e.g., peer or student-faculty relations) are less pronounced and faculty judgment of students' competency is pivotal. In the third stage, the period from candidacy to final defense, the dissertation committee heavily influences persistence.

Strayhorn (2005) identified three categories of factors that are related to graduate student persistence: economic factors (e.g., financial assistance), academic factors (e.g., standardized test performance), and nonacademic factors (e.g., age, gender, marital status). In sum, these doctoral persistence models show that attainment of the doctorate is a longitudinal process that is influenced 
by both institutional and personal factors. To understand the complex interplay of these factors in relation to TTD, we developed an integrated conceptual scheme of doctoral persistence that draws on the theoretical works in prior studies. Specifically, to understand the structures and processes that lead to TTD, we used a systems approach in which doctoral persistence is conceptualized as a system with three interrelated elements - input, processes, and output. The doctoral persistence models discussed identify background characteristics such as student gender, ethnicity, and age that we view as inputs to the system. Tinto (1993) noted that upon entry into a department, students experience academic and social integration, to which we add economic integration and personal attributes. Students experience varying levels of integration in these four domains, which constitute the process element.

Students' level of satisfaction with their academic performance, degree of involvement in program activities, and curriculum structure constitute academic integration. Academic integration is present in Tinto's (1993) model, and it subsumes academic variables in Strayhorn's (2005) model and the variables grades and involvement in Girves and Wemmerus's (1988) model. Social integration refers to the nature of interaction that students experience with peers and faculty as they engage in departmental activities. It is present in Tinto's (1993) model and is surrogated by alienation/isolation in Girves and Wemmerus's (1988) model. The degree to which students' financial needs are met while pursuing the doctorate constitutes economic integration. Economic integration is proxied as economic variables in Strayhorn's (2005) model and as financial support in Girves and Wemmerus's (1988) model. Although not featured by the persistence models reviewed, the last domain, personal attributes, refers to certain psychological traits (e.g., motivation) that students possess and which are related to their goals and commitments while pursuing the doctorate.

We hypothesized that high levels of integration in the four domains are associated with timely completion. In our integrated model, the domains are deemed as being complementary such that low levels of integration in one or more domain is compensated by high levels of integration in the other domains for timely doctorate completion to be achieved. The ultimate outcome, TTD, thus constitutes the output of the system. Hereafter, the term TTD refers to elapsed TTD, namely, the number of years that elapse from entry into a doctoral program to the time the doctorate is attained, including periods of breaks from active enrollment.

The philosophical stance that drove this mixed research study is what Johnson (2009) recently has labeled as dialectical pragmatism. This philosophical stance refers to an epistemology wherein the researcher incorporates multiple epistemological perspectives. Specifically, in the present study, the following two epistemological perspectives were combined: pragmatism-of-the-middle and constructivism. According to Onwuegbuzie, Johnson, and Collins (2009), pragmatism-of-themiddle "offers a practical and outcome-oriented method of inquiry that is based on action and leads, iteratively, to further action and the elimination of doubt; paradigms routinely are mixed" (p. 134). In contrast, constructivism, specifically, social constructionism, focuses more on social processes and interactions (Schwandt, 2007). Moreover, the goal of social constructionism is to understand through reconstructions and vicarious experiences of participants. According to Schwandt (2007), social constructionism emphasizes the person's interpretation of the situation of interest, how social people recognize, produce, and reproduce social actions, and how they come to share an intersubjective understanding of specific life circumstances. 


\section{Method}

\section{Institutional Context}

This study was conducted on a college of education located at a southeastern public university in the United States, an institution classified as a research university with a very high level of research activity (The Carnegie Foundation for the Advancement of Teaching, n.d). The college is a large urban college with eight departments and is accredited by the National Council for Accreditation of Teacher Education (NCATE).

The college was awarding undergraduate degrees and offering advanced degree programs leading to the Doctor of Philosophy (Ph.D.), Doctor of Education (Ed.D.), Master of Education (M.Ed.), Master of Arts (M.A.), Master of Arts in Teaching (M.A.T.). At the time of data collection, there were at least 24 instructional programs (e.g., Adult Education, Educational Psychology, Instructional Technology, Mathematics Education, and Special Education) leading to either a Ph.D. or an Ed.D. The structure and curriculum of doctoral programs in Education at this college, like most US schools, is as follows: (a) completion of Masters degree prior to admission is required, (b) for most students, the Masters is a professional degree rather than a research or scholarly degree, (c) extensive coursework prior to candidacy often is required, (d) most students are not funded by the program, and (e) most students do not work in a faculty member's research.

\section{Study Design}

A partially mixed sequential dominant status design (Leech \& Onwuegbuzie, 2009) was employed whereby the quantitative phase preceded the qualitative phase (see Figure 1). The statistical data in the first phase provided an empirical basis for selecting a sample of participants for the qualitative phase. The qualitative phase (i.e., QUAL) is capitalized to indicate that it was given more weight with respect to addressing the research question, "What factors influence TTD?" Integration of findings from both phases occurred after data analyses were completed, making it partially mixed (Leech \& Onwuegbuzie, 2009). Although the quantitative phase was based on a limited number of variables, it provided complementary data to the narrative data (themes) in the qualitative phase. Triangulation of secondary data on students, student interviews, and faculty focus groups was expected to enhance credibility of the findings (Creswell, 2007).



Figure 1. Partially mixed sequential dominant status design 


\section{Quantitative Phase}

\section{Data source and sampling}

The Dean's office provided secondary data on 1,028 College of Education doctoral students (level-1) who were admitted into either a Ph. D. or an Ed. D. program between spring of 1990 and spring 2006. These students were nested within 24 programs (level-2): 18 Ph. D. and 6 Ed. D. programs. This translated to approximately 43 students per program and was predominantly White female (75\% White, $69.1 \%$ female).

\section{Variables}

The student-level data analyzed in this study were gender, age, ethnicity, master's grade point average (GPA), and graduate record examination (GRE) scores. The program-level variables were size of the program (i.e., the number of students admitted per year), size of the department housing the program (i.e., the number of programs in the department housing the program), the proportion of Whites admitted into the program, and the proportion of females admitted in the program. The continuous student-level variables were aggregated at the program level to obtain mean values.

\section{Data analysis}

We employed a discrete-time multilevel event history modeling, which involves a combination of event history modeling (an analytic technique that allows for inclusion of information of censored students, also called hazard analysis or survival analysis; Allison, 2001) and multilevel modeling (an analytic technique that considers the clustering of students into programs; Raudenbush \& Bryk, 2002), to analyze the data. Letting $h_{i j t}$ index the entire log hazard profile of doctorate attainment for student $i$ in program $j$ in year $t, T_{i j t}$ be a dummy indicator of year $t$ for student $i$ in program $j$, then using a logit link to regress the binary event indicator (graduation) on all the time dummies yields a multilevel logistic model expressed in the combined form as follows:

$\eta_{i j t}=\sum_{t=1}^{10} \gamma_{\mathrm{t}}\left(T_{i j t}\right)+\gamma_{1} \mathrm{x}_{1 j}+\gamma_{2} \mathrm{x}_{2 j}+\ldots+\gamma_{\mathrm{n}} \mathrm{X}_{n j}+u_{j 0}, \quad u_{j 0} \sim N\left(0, \tau_{00}\right)$ where $\eta_{i j t}$ is the log odds of doctorate attainment, $\gamma_{t}$ is the average intercept across program units at time $t ; \gamma_{1}$ to $\gamma_{\mathrm{nj}}$ are regression slopes expressing the direct effect of student- and program-level variables on the log odds of doctorate attainment, and $u_{j 0}$ is the unique increment to the intercept associated with program unit. We estimated the logit of the hazard using NLMIXED, a SAS procedure that allows for modeling the nesting of students into programs (SAS Institute Inc., 2009). The use of discrete-time multilevel event history to model TTD allowed us to include information about students who do not persist to completion (also referred to as censored cases) but are argued to "contribute" information in the computation of TTD. For instance, in computing median TTD, we consider censored cases alongside students who graduate (see Wao, 2010, for detailed explanation of this methodology). This approach, we argue, is more accurate compared to, for example, how Jiranek (2010) computed average time to completion in which information about censored cases is ignored.

\section{Qualitative Phase}

\section{Sampling}

We computed median TTD based on secondary data in the quantitative phase and used it as a reference point to identify two extreme cases for the qualitative phase. The long TTD case com- 
prised two doctoral programs where median TTD was among the longest, 7.2 and 8.0 years, whereas the short TTD case comprised two programs where median TTD was the shortest, 3.6 years. In this case, we refer to doctoral programs such as Mathematics Education, Instructional Technology, School Psychology, and so on, which are typical programs in the College where the study was conducted. With students and faculty as the units of analysis, we were able to describe in detail each case and themes within it to establish patterns (within-case analysis) and conduct thematic analysis across the cases (cross-case analysis) (Yin, 2009).

Student participants were purposefully recruited and had to have completed all requirements for earning the doctorate except the dissertation (i.e., all-but-dissertation (ABD) stage) or attained the doctorate within three years prior to the date of participation. A faculty member had to be at least an associate professor, must have served on at least five dissertation committees, and must have been in the department for at least five consecutive academic years. Participants meeting these criteria were considered information rich because they had adequate experience with the process of attaining the doctorate. Besides students' perceptions, in this study, faculty perspectives were deemed germane to understanding factors influencing TTD in that they are the primary agents of integration in a department (Golde, 2000), serving as 'role models and mentors,' and inculcating into students the "norms, expectations and standards of acceptable performance for the field" (McFarland \& Caplow, 1995, p. 3).

\section{Instruments}

Data were collected using an interview protocol and a focus group questioning route (sequence of questions). Four individual student interviews (two from each case) and two four-member faculty focus groups (one from each case) were conducted. The questions were semi-structured, progressing from simple opening questions (e.g., "What motivated the pursuit of the doctorate?"), to complex transition and key questions (e.g., "Think back and identify factors that influenced the TTD"), and back to simple ending questions (e.g., "Classify the factors as either institutionrelated or personal and state which of these two contributed most to TTD"). Two educational researchers with expertise in measurement and evaluation provided feedback that ensured the questions were understandable and likely to elicit relevant responses.

\section{Recruitment}

The chairpersons of identified departments provided lists of potential participants (41 students, 20 faculty members) from which those meeting the selection criteria (18 students, 12 faculty members) were sent a generic email describing the purpose of the study, its importance, and a request to participate. A personalized follow-up email was sent a week before the meeting date indicating the time and venue of the session and a request to confirm participation. Of those who responded (nine students, 10 faculty members), four students and eight faculty members participated.

\section{Actual sessions}

One interview was conducted inside the interviewee's office whereas the others took place in a quiet room inside the library. Focus groups were conducted in a conference room furnished with ergonomic chairs and a round table. These venues had minimal distractions. Each individual interview took approximately one hour, whereas each focus group each lasted for approximately 90 minutes. Prior to each session, the interviewer or moderator explained the purpose of the study, emphasized the importance for participation, and gave assurance that no anticipated risks were associated with participating. The participant consented to the tape-recording of the session to maximize descriptive validity (Maxwell, 1992). To preserve confidentiality, participants were assigned pseudonyms (names of the planets for students; zodiac/stars names for faculty mem- 
bers). Whenever a vague comment was given, and it was believed that extra information existed, participants were probed to provide further explanation.

\section{Data analysis}

Data analysis was conducted in stages. First, the entire transcript was read, taking note of significant statements (i.e., statements containing a word or phrase that captured a particular theme associated with TTD). Next, making efforts to preserve the original language and sentence structure of each statement, significant statements were coded or unitized (i.e., categorized into units) such that each code corresponded to a unique, non-repetitive significant statement. We used in vivo coding (based on participants' exact words) and deductive coding (based on theory), constantly comparing each code with preceding ones to avoid redundancy. The third step involved aggregating codes containing statements similar in content to form themes, making conscious efforts to bracket out any beliefs or assumptions that might have arisen from prior knowledge (e.g., literature review) and experience (i.e., epoche; Moustakas, 1994). To facilitate both within-case analysis (treating data from the two faculty focus groups as single case) and cross-case analyses (organizing data from the faculty focus groups into long TTD and short TTD cases), themes were $b i$ narized. That is, for each participant, the theme was scored " 1 " if one or more significant statements made by the participant was classified under that theme, and scored " 0 " otherwise (Onwuegbuzie, 2003; Onwuegbuzie \& Teddlie, 2003). This process yielded a participant by theme (inter-respondent) matrix and a unit by theme (intra-respondent) matrix (Onwuegbuzie, 2003; Onwuegbuzie \& Teddlie, 2003). The frequency effect size ([FES]; Onwuegbuzie \& Teddlie, 2003), the percentage of participants who endorsed a theme, and intensity effect size ([IES]; Onwuegbuzie \& Teddlie, 2003), the percentage of statements referring to a particular theme, were computed based on information in the inter-respondent and intra-respondent matrices, respectively. To obtain a measure of consensus in the endorsement of themes, the FES and IES were transformed into percentile ranks $(\mathrm{pR})^{1}$, the percentage of themes that fall below a given theme. The strength of association of each theme with TTD was defined as minimal if $\mathrm{pR} \leq 25 \%$, moderate if $\mathrm{pR}$ was between $25 \%$ and $\leq 74 \%$, and strong if $\mathrm{pR} \geq 75 \%$. The strategy of computing and ranking of effect sizes, Onwuegbuzie and Teddlie (2003) argue, allows for extracting a greater amount of information from the qualitative data. Data analysis was performed using ATLAS.ti, a qualitative data analysis software program. Intercoder agreement of more than .80, computed using Cohen's kappa, was achieved across all themes.

\section{Legitimation of findings}

Besides identifying extreme cases and computing the effect sizes, various techniques were employed to enhance legitimation of the findings. Specifically, to obtain accurate description of factors perceived to influence TTD, we gathered views of students and faculty (data triangulation; Denzin, 1978), different individuals served as moderators and note-takers (investigator triangulation; Denzin, 1978), different researchers performed data analysis (multiple-analyst triangulation; Miles \& Huberman, 1994), focus group sessions were spread over a period of 8 months including informal interactions with the participants during this period (prolonged engagement; Lincoln \& Guba, 1985), post-session reflective dialogues with participants were held (debriefings; Lincoln

${ }^{1} \mathrm{pR}=\left[\frac{\mathrm{f}_{\mathrm{b}}+1 / 2 \mathrm{f}_{\mathrm{w}}}{\mathrm{N}}\right] X 100$ where:

$\mathrm{f}_{\mathrm{b}}=$ number of themes whose effect sizes are less than the effect size of the theme in question; $\mathrm{f}_{\mathrm{w}}=$ number of themes with the same effect size as the theme in question (including theme in question);

$\mathrm{N}=$ Total number of themes cited by the group (case) being analyzed 
\& Guba, 1985), and detailed data including near verbatim transcripts on verbal and nonverbal cues were collected (thick descriptions; Geertz, 1973).

\section{Integration of the findings}

After undertaking quantitative and qualitative data analysis separately, results were integrated into one coherent whole at the data interpretation stage. Significant factors from the quantitative phase were compared with factors identified in the qualitative phase to identify commonalities and differences in the findings (i.e., data comparison, data integration; Onwuegbuzie \& Teddlie, 2003). Data triangulation also allowed for corroborating results from the two phases (Greene, Caracelli, \& Graham, 1989). Because participants in the qualitative phase comprised a subset of the quantitative sample, the assessment of inferences was less problematic; that is, the sample integration threat (i.e., the extent to which the relationship between the quantitative and qualitative sampling designs yields quality meta-inferences) was minimized (Onwuegbuzie \& Johnson, 2006).

\section{Results}

\section{Quantitative Phase}

Discrete-time multilevel event history modeling revealed that the median TTD was 5.8 years, a finding that coincided with 5.82 years in Civian's (1990) study, which also focused in Education. As shown in Table 1, students were most likely to attain the doctorate in the seventh year (the values for year 10 are inflated as they are based on a reduced risk sets) but Civian found that the likelihood of doctorate attainment was highest during the fifth, sixth, and seventh years.

Table 1. Predictors of the Timing of Doctorate Attainment $(N=1,028)$

\begin{tabular}{lll}
\hline Predictor & Log odds (Standard error) & Odds Ratio \\
\hline Year 1 & $-4.92(0.64)^{*}$ & 0.01 \\
Year 2 & $-4.17(0.61)^{*}$ & 0.02 \\
Year 3 & $-3.50(0.59)^{*}$ & 0.03 \\
Year 4 & $-3.02(0.57)^{*}$ & 0.05 \\
Year 5 & $-2.36(0.56)^{*}$ & 0.09 \\
Year 6 & $-2.28(0.58)^{*}$ & 0.10 \\
Year 7 & $-1.79(0.61)^{*}$ & 0.17 \\
Year 8 & $-2.16(0.70)^{*}$ & 0.12 \\
Year 9 & $-2.62(0.00)^{*}$ & 0.07 \\
Year 10 & $-1.12(1.00)$ & 0.33 \\
Student's master's GPA (grand-mean centered) & $0.95(0.31)^{*}$ & 2.59 \\
Size of the department housing the program & $-0.17(0.04)^{*}$ & 0.84 \\
Proportion of female students in the program & $2.66(0.72)^{*}$ & 14.3 \\
GRE-Quantitative (grand-mean centered) & $0.01(0.002)^{*}$ & 1.01 \\
Variance & $0.82(0.52)$ & \\
\hline AIC & 2309.4 & \\
-2LL & $2277.4(\Delta=62)$ & \\
Note. ${ }^{*} p<.05 ;$ Variance $=$ between-program variance representing random effect; AIC = Akaike Information \\
Criterion; LL = Log likelihood; $\Delta=$ change in -2LL when compared with the values in the baseline model.
\end{tabular}

With respect to student level factors, a student's master's GPA was statistically significantly and positively associated with the odds of doctorate attainment, a finding that seemed to contradict Bair's (1999) in which academic achievement indicators were found not to be predictive of TTD. It was unclear, however, in Bair's meta-synthesis whether master's GPA was one of the academic achievement indicators considered. Preliminary analysis (not shown) undertaken as part of the 
model-building process indicated that student-level variables, including race, age, GPA, and GRE verbal score at admission, were not significantly related to TTD whereas the significance of gender in favor of female students disappeared when program-level covariates were included in the model, a finding that contradicts Stiles's (2003) in which gender was a significant predictor of the propensity to graduate.

With respect to program-level factors, the size of a department housing the program, proportion of female students, and mean GRE quantitative score were statistically significantly associated with the timing of doctorate attainment. A decrease in the size of the department housing the program was associated with a statistically significant increase in the odds of doctorate attainment in the program, a finding that agrees with the literature indicating that smaller departments are associated with shorter TTD (Bauer 2004; Boyle \& Boice, 1998; Dinham \& Scott, 1999; Ferrer de Valero, 2001). The higher the proportion of female students or the mean GRE quantitative score, the higher the odds of doctorate attainment in any given year in the program, other factors held constant. Other program-level factors including the number of students enrolled in a program (program size), percentage of White students, and mean values of age, GPA, and GRE-verbal were not statistically significantly related to TTD.

\section{Qualitative Phase}

\section{Characteristics of participants}

Focus groups. As shown in Table 2, faculty members in the focus groups were predominantly White males and were advanced in their institutions (at least an associate professor). The long TTD case, compared to the short TTD case, included faculty members who had been in their departments longer, served in more dissertation committees, and chaired or co-chaired more committees. Faculty members from long TTD case self-reported spending almost one half of their time on teaching but less time on research, advising, and administrative tasks. Overall, faculty members reported spending more of their time on teaching than on research (i.e., $36 \%$ vs. $22 \%$, respectively).

Table 2. Background Characteristics of Faculty Focus Groups

\begin{tabular}{|c|c|c|c|c|c|c|c|c|c|c|}
\hline Faculty & Race & Sex & Rank & Years & D1 & D2 & $\begin{array}{l}\text { Teach } \\
\%\end{array}$ & $\begin{array}{l}\text { Research } \\
\%\end{array}$ & $\begin{array}{l}\text { Advice } \\
\%\end{array}$ & $\begin{array}{l}\text { Admin } \\
\%\end{array}$ \\
\hline Aries* & White & Male & Professor & 38 & $>100$ & $>100$ & 60 & 20 & 10 & 10 \\
\hline Taurus* & White & Male & Associate & 17 & $>100$ & 20 & 70 & 10 & 20 & 0 \\
\hline Gemini* & White & Male & Professor & 24 & $>57$ & $>50$ & 50 & 35 & 15 & 0 \\
\hline Leo* & White & Female & Professor & 18 & $>30$ & $>25$ & 15 & 15 & 15 & 55 \\
\hline \multicolumn{4}{|c|}{ Average (For long TTD case) } & 24 & $>72$ & $>49$ & 49 & 20 & 15 & 16 \\
\hline Virgo & White & Female & Associate & 10 & $>13$ & 12 & 30 & 15 & 25 & 30 \\
\hline Libra & White & Male & Professor & 13 & $>35$ & 30 & 30 & 50 & 15 & 5 \\
\hline Scorpio & White & Male & Professor & 7 & $>100$ & $>35$ & 25 & 25 & 25 & 25 \\
\hline Capricom & White & Male & Associate & 10 & $>20$ & $>10$ & 15 & 0 & 25 & 60 \\
\hline \multicolumn{4}{|c|}{ Average (For short TTD case) } & 10 & $>42$ & $>22$ & 25 & 23 & 23 & 30 \\
\hline \multicolumn{4}{|c|}{ Average (For both cases) } & 17 & $>57$ & $>36$ & 36 & 22 & 19 & 23 \\
\hline \multicolumn{11}{|c|}{$\begin{array}{l}\text { Note: * Indicate a faculty member in a department housing program classified as long TTD program: } \\
\text { D1 = Number of dissertation committees in which a faculty member served; D2 = Number of } \\
\text { dissertation committees a faculty member chaired or co-chaired; Teach = self-reported estimate of } \\
\text { percent of time dedicated to teaching; Research = self-reported estimate of percent of time dedicated } \\
\text { to research; Advice = self-reported estimate of percent of time dedicated to advising; Admin = self- } \\
\text { reported estimate of percent of time dedicated to administrative tasks. }\end{array}$} \\
\hline
\end{tabular}


Interviews. Table 3 shows that students interviewed comprised one African American female, two White males, and one White female (Table 3). Their ages at admission ranged from 27 to 54 years and they had high GPA score (at least 3.4) and moderate GRE scores (at least 500, except for Venus who scored 450). Besides Pluto who had attained the doctorate, other participants were in the ABD stage, having taken between four and eight years pursuing the doctorate without stopping out.

Table 3. Background Characteristics of Student Interviews

\begin{tabular}{llllllllll}
\hline Interviewee & $\begin{array}{l}\text { Program } \\
\text { (Case) }\end{array}$ & Race & Sex & Age & GPA & $\begin{array}{l}\text { GRE } \\
\text { Verbal }\end{array}$ & $\begin{array}{l}\text { GRE } \\
\text { Quantitative }\end{array}$ & Stage & $\begin{array}{l}\text { TTD* } \\
\text { (years) }\end{array}$ \\
\hline Venus & Short TTD & Black & Female & 27 & 3.6 & 450 & 430 & ABD & 7 \\
Pluto & Short TTD & White & Male & 49 & 3.4 & 500 & 600 & PhD & 4 \\
Mars & Long TTD & White & Male & 39 & 3.5 & 500 & 600 & ABD & 8 \\
Mercury & Long TTD & White & Female & 54 & 3.5 & 500 & 500 & ABD & 4 \\
\hline
\end{tabular}

* If a student is in the ABD stage then years so far spent pursuing the doctorate is indicated.

\section{Goals for pursuing the doctorate}

According to the faculty members, most students pursue the doctorate in Education majorly for economic reasons: "to get higher salaries, "to get a job," "[it] allows for more flexibility in terms of work," and "professional development and growth of opportunities." In contrast, three nonmutually exclusive categories of goals for pursuing the doctorate were identified from student interviews. Pluto, a practicing counselor, had both academic and economic goals: “... to allow me

Table 4. Themes Associated with TTD

\begin{tabular}{|c|c|c|c|c|c|c|}
\hline \multirow{3}{*}{$\begin{array}{l}\text { Factors/Themes } \\
\text { (1) }\end{array}$} & \multicolumn{3}{|c|}{ Frequency Effect Size (FES) } & \multicolumn{3}{|c|}{ Intensity Effect Size (IES) } \\
\hline & (2) & (3) & (4) & (5) & (6) & (7) \\
\hline & $\begin{array}{c}\text { Combined } \\
(n=8)\end{array}$ & $\begin{array}{l}\text { LTTD } \\
(n=4)\end{array}$ & $\begin{array}{l}\text { STTD } \\
(n=4)\end{array}$ & $\begin{array}{r}\text { Combined } \\
(239)^{* 3}\end{array}$ & $\begin{array}{l}\text { LTTD } \\
(83)^{*}\end{array}$ & $\begin{array}{l}\text { STTD } \\
(156)^{* s}\end{array}$ \\
\hline Academic & & & & & & \\
\hline Structure & Strong & Strong & Strong & Strong & Strong & Strong \\
\hline Preparation & Strong & Strong & Moderate & Strong & Strong & Strong \\
\hline Enrollment & Strong & Strong & Moderate & Strong & Moderate & Strong \\
\hline Communication & Moderate & Moderate & Moderate & Moderate & Moderate & Moderate \\
\hline Topic & Moderate & Strong & Weak & Moderate & Moderate & Weak \\
\hline Social & & & & & & \\
\hline Advising & Strong & Moderate & Strong & Strong & Strong & Strong \\
\hline $\begin{array}{l}\text { Support to faculty } \\
\text { Economic }\end{array}$ & Moderate & - & Strong & Moderate & - & Strong \\
\hline Work & Moderate & Moderate & Moderate & Moderate & Moderate & Moderate \\
\hline $\begin{array}{l}\text { Financial support } \\
\text { Personal }\end{array}$ & Moderate & Moderate & Moderate & Moderate & Moderate & Moderate \\
\hline $\begin{array}{l}\text { Motivation } \\
\text { External }\end{array}$ & Moderate & Moderate & Moderate & Strong & Moderate & Moderate \\
\hline $\begin{array}{l}\text { Family obligations } \\
\text { Life events }\end{array}$ & $\begin{array}{l}\text { Strong } \\
\text { Moderate }\end{array}$ & Strong & $\begin{array}{l}\text { Strong } \\
\text { Moderate }\end{array}$ & $\begin{array}{l}\text { Moderate } \\
\text { Moderate }\end{array}$ & Moderate & $\begin{array}{l}\text { Moderate } \\
\text { Moderate }\end{array}$ \\
\hline
\end{tabular}


to learn better skills of how to 'teach' adults." Mars' comments, "I saw this [name of program] was something useful in teaching, it offers some way to evaluate learning" as well as Mercury's, "My original goal was not to do research, rather, to teach...but I changed because I found that I really liked research" were classified as academic. Only Venus cited personal reasons for pursuing the doctorate: "just for self-satisfaction." Faculty members made 239 statements ( 83 by the long TTD case and 156 by the short TTD case) with a mean of 30 statements per member. Table 4 presents a summary of themes that were at least moderately shows factors associated with TTD based on the combined cases (columns " 2 " and "5").

\section{Academic integration factors}

Structure, defined as the nature and arrangement of curriculum tasks and resources, was frequently and intensely cited by faculty members as being associated with TTD. Faculty members from long TTD programs cited "collecting feedback from students, constantly revising the program," and "...making summer offering available" as structural measures that were being undertaken to achieve timely completion. Faculty members from short TTD programs stated that their students "move in a pretty locked-step in terms of the time sequence" and "have to take the courses when they are offered." Focus groups members unanimously agreed that most Ph.D. programs in the college were among "the longest degrees in terms of hours so far in the country." One faculty member was very specific, "The Ph.D. program in this college, from what I know, is the second longest doctoral program in the USA... places like Vanderbilt right now are having only nine hours of dissertation... that takes the program down on hours!"

Responses from interviews were consistent with faculty members' sentiments. Elements of program structure identified by students included number of credit hours, course sequencing, rigor of courses, and practical application of courses. Venus expressed satisfaction with the structure of her program, particularly the coursework phase, which she reported, was "pretty much structured to where you know which classes to take." Although the coursework was very heavy, involving 18 credit hours during the first semester, she viewed them as challenging and relevant to her professional goals: "I have grown professionally in terms of writing skills, the way I view things and think about things have expanded." Pluto was dissatisfied with the pedagogy noting that some professors "are interested in saying this is how you do it ...too involved in the product than the process." Students' progress is impeded, especially at the dissertation stage, because they spend a lot of time learning the material through other means if they did not during coursework. Mars and Mercury, both from long TTD programs, expressed dissatisfaction with the sequencing of coursework stating that they were forced to take some courses when they felt "not ready," which led to having "incomplete [courses]." They also cited the lack of practical application of materials learned during coursework. Mars stated that he was exposed to "...different programs [software] but no practical hands-on experience with any technology." He preferred gaining practical experience alongside coursework to completing the degree: "When I took a course, the next semester I forgot what I did the previous semester so hands-on experience is what I wanted." Similarly, apart from the requirement that students must co-teach with a professor, Mercury commented, "There was no work requirement, just take courses, pass the quals [qualifying examinations] and do your dissertation." She recommended that conducting research be a formal requirement for graduation as it is: "really a good way to learn and be mentored."

Preparation (i.e., the amount and quality of academic preparation a student received) was frequently and intensely cited by faculty members as being associated with TTD. Coursework and acquisition of writing and research skills were mentioned as important components of preparation. Faculty members from long TTD programs cited ill-preparation of students from their programs: "they have a problem with their research tools... statistics and methods course" and "some have anxiety about writing and that slows them down." In contrast, students from short TTD pro- 
grams were perceived as being well prepared: "they take opportunities to work with faculty members and get involved in studies that might then lead to a dissertation."

Although absent from student interviews, comments from the faculty members indicated that a student's enrollment status had a strong association with TTD: "the whole idea of part-time or full-time is a major difference in length" and "part-time [enrollment] slows them down." Focus groups suggested that most short TTD programs were full-time whereas almost all long TTD programs were part-time.

Communication, defined as the clarity and timeliness of information related to program expectations and requirements to students was, according to responses from faculty, moderately associated with TTD. Faculty members from short TTD programs communicated with incoming students in multiple ways: "We try to make it very clear before people even get to the interview stage that the expectancy in our program heavily emphasizes research," "We have one of our students automatically contact them," and "We run a 1-week orientation." Student interviews suggested program information was communicated in multiple ways. Venus attended a 4-day orientation including a tour of the campus and faculty-student luncheon that provided her the opportunity to meet new and old students. She received a handbook that "pretty much outlined what had been stated at the orientation." Pluto learned of the program expectations by reading the university catalogue, a mode of communication with which he was comfortable. Mars learned about the program expectations from his advisor: "Dr. _ laid out a program of study so pretty much I followed that"; however, he ended up taking more courses than was required because he "wanted to learn more." Mercury relied on the Internet to access program information but supplemented these with advice sought from faculty, peers, and her advisor.

Responses from the faculty members suggested that the nature of the dissertation topic chosen had a moderate association with TTD. The tenor of comments from faculty from long TTD programs was that their students tend to struggle in conceptualizing "a valid dissertation topic" or "research questions that can be answered," whereas those from the short TTD programs noted that their students tended to think of the dissertation in terms of a continuation of the Ed.S. thesis: "whatever they do, their Ed.S. thesis on becomes the foundation for their dissertation." Student interviews corroborated sentiments of faculty. Contrasting herself with students who relied on data from professors' research projects for their dissertations, Venus passionately described her topic: "I wanted to do something that I'm proud of and say is a representation of my work, not doing something because it is the quickest way to get out of the program." However, because her topic was not reliant on data obtained from any professor's research project, she felt that she "almost had to sell it to them." Pluto, like Venus, passionately emphasized the applicability of his topic to real life, "I designed a real classical design with pre-, post- and follow-up testing - a real experiment with real people." Although Mars did not have a solid idea for a topic, he cited interest in the topic, familiarity with the technique to be used, and data availability as factors he would consider in identifying one. Having abandoned her first two topics due to data inaccessibility, Mercury was passionate about her topic, which was based on data from a collaborative project with a fellow doctoral student and one of her committee members. Except for its breadth, she felt she had ownership of it.

\section{Social integration factors}

Advising, defined as academic guidance, mentoring, and supervising of students, was frequently and intensely cited by faculty members as being associated with TTD. Faculty members stated that if advisors "meet monthly with students" and "provide that kind of support [timely feedback to students]" then "those students finish at [a] much more rapid rate." They noted that the personality of the advisor is crucial: "some see mentoring of their students as critical part of their role 
and others see it as kind of a pain in the neck." One faculty remarked that older faculty tend to spend more time with students than do younger ones: "... us old folks are more inclined to want to work and spend more time with students than the younger faculty who see that as time taken away from them to do research and money." Echoing faculty sentiments, Venus noted that doctoral students are expected to be independent, however, "... it would be good to have some guide to get you there." She decried timely feedback from her advisor: "... just getting constant feedback... once in every couple of weeks is not asking too much but to him [advisor] it seems a lot."

Closely related with advising is the characteristics of the dissertation committee that a student forms, which according to students' comments, was associated with TTD. Apart from taking classes taught by her dissertation committee chair, Venus did not get a chance to work closely with him. Despite several attempts to initiate communication including emailing, she was not able to "pin him down for a time to meet," which was traumatizing to Venus. She was so emotional while sharing her experience that the interviewer almost suggested seeking the help of a counselor. However, her tone changed when she began narrating how she learned that other students had similar experiences with this professor. By following the advice from peers and faculty members, their relationship improved: "We are now able to meet, we have an understanding... we gonna move from there and see how it works out." Pluto, in constituting his committee, focused on people who were conversant with his topic and could "look at [his] research design and make valid comments if not corrections." Overlooking the personality of committee members was, however, costly to his progress. One member of his committee deliberately refused to give feedback despite frequent attempts to contact her: "I could send her emails... go by her office but she wasn't there. I never got feedback!" Pluto's attempts to discuss the problem with the committee chair, who, in turn, tried to talk to this faculty member, yielded no fruits: "nasty comments were made back to me." She even refused to be removed from the committee: "she said that I never sent her anything [but] I went back to my email and proved that I was trying to talk to her." Although parts of Mars's and Mercury's committee were chosen without their input, they were satisfied with the help they received from them. Mars stated that it was explained to him later that "they were trying to get students spread out across faculty in the department." Factors that students considered in choosing faculty to serve in the committee varied. Mars chose one member of his committee because he was "laid back" but later learned that he was due for retirement. Mercury's second committee member was chosen because she was "an extremely open-giving woman" and the other was a professor with whom she had taken many courses. Mars and Mercury had to replace members of their committee who left the university.

Although absent from the student interviews, comments of faculty members from short TTD programs suggested that the degree of support to faculty due to their involvement in advising, mentoring, and apprenticeship tasks had a moderate association with TTD. Heavy workload deterred faculty from offering adequate advising: "How much individual support [advising] can you give when you are supposed to be teaching 2 to 3 classes a semester and research on top of that?" They recommended that the College should consider seriously how to support faculty, especially during the summer, to enable them provide adequate advising.

\section{Economic integration factors}

Responses from faculty indicated that the nature of work and financial support a student received were moderately associated with TTD: "financial support is the number one issue for everybody...a key factor for students whether it is fulltime or part-time program." Faculty noted that "when they [students] get a job, it is more difficult for them to finish their dissertation." Students perceived working on-campus (e.g., as graduate assistant) as enhancing completion. Mercury noted that working fulltime [off-campus] during coursework "was overwhelming," however, when she gave up outside employment, "it was much easier to be focused" because her work as a 
graduate assistant "revolved around the study that [she] was doing." She attributed her progress to a dual involvement: "I had to take the risk to quit the job and the institution helped with the GA [graduate assistant] to pay the tuition and stipend to support my living." She noted, "students may be working for cheap [but] the jobs revolve around what [they] are learning" thereby contributing to timely completion.

\section{Personal attributes}

Motivation, defined as the desire to work and to attain set goals despite obstacles encountered, was intensely cited but with moderate frequency to be associated with TTD. Faculty members noted, "the overriding issue has always been personal attributes [drive] of the students," that is, "drive of students just to get it done" or "student's personal attributes in terms of drive and discipline." It enables them to "keep the focus...to keep going" despite obstacles encountered. Faculty from long TTD programs mentioned that some of their students had negative attitudes towards coursework or dissertation: "they don't even wanna think about it [statistics courses]" and "they are hoping that they can substitute the quantitative research courses with qualitative research courses," sentiments which echoed Venus's view of the dissertation: "it is just an extra thing, I think of it as one extra requirement." Not only did student interviews identify motivation as an important factor, it also identified different sources of motivation. According to Venus, having "somebody who was pushing her," somebody who was willing to maintain steady communication with her, and structured coursework were sources of motivation to attain the doctorate in a timely fashion. However, her confidence level dropped when she learned that she did not pass the qualifying exams: "Fear kicked in, I was afraid to even try." Part of Pluto's motivation to attain the doctorate in a timely manner stemmed from his passion for the dissertation topic: "... it was such a pleasure. I got a lot of satisfaction from it...there were a lot of obstacles but I was determined."

\section{External factors}

Family obligation was frequently cited but with moderate intensity as being associated with TTD. Faculty members' comments included: "We have family tied to these reasons, you can't leave your family behind." Echoing faculty, students' comments suggested that family obligations influenced TTD. Venus noted that "it [pursuing the doctorate] is not an easy process" and that taking care of her father who had leukemia was "not really a deterrent but an occasional distraction." Pluto cited "birth of baby" as an example of event that might distract a student while pursuing the doctorate.

\section{What matters most: Institutional or personal factors?}

Although not mutually exclusive, factors that influence TTD may be categorized as personal or institutional. Personal factors may be conceived as characteristics specific to a student's situation (e.g., gender and motivation) and are not directly controlled by the institution, whereas institutional factors are those over which the institution has control (e.g., department policies and advising). Although various institutional factors were cited in the interviews, interestingly, when asked to sum as either "institutional" or "personal" the factors that influenced their TTD the most, only one interviewee (Pluto) stated that institutional factors played a major role. Like students, most faculty members (5 out of 8 ) cited personal factors, one cited institutional factors, and two stated the factors were interlinked.

\section{Discussion}

The results of the quantitative and qualitative phases suggest that factors related to TTD are intertwined and involve a complex interplay of institutional and personal factors. We provide an 
updated integrated conceptual scheme of TTD (Figure 2). It is worth noting that this version includes external factors that were not included in the earlier version.

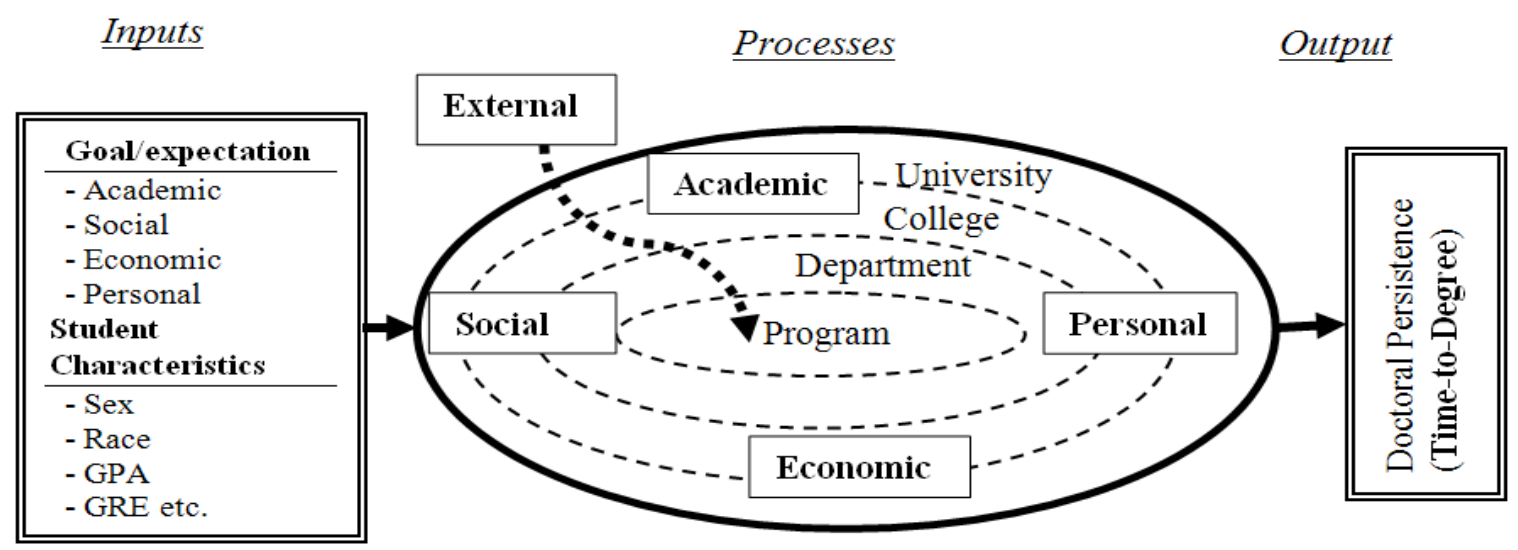

Figure 2. Revised integrated conceptual scheme of TTD

\section{Why do Students Pursue the Doctorate in Education?}

Data related to goals for pursuing the doctorate came from the qualitative phase only. A divergent finding is that most students ( 3 out of 4 ) cited academic goals for pursuing the doctorate, whereas the perception of faculty suggested that most students pursue the doctorate for economic reasons. Previous research supports both findings. In Dinham and Scott's (1999) study, whereas $60 \%$ of the participants cited academic for pursuing the doctorate (e.g., the desire to study at greater depth or improve one's skills), economic reasons (e.g., promotion and career improvement) were more powerfully expressed. It is unclear if differences in goals exist. It might be that the driving force behind students' choices (e.g., interest in their respective disciplines and the motivation to become part of the academy) is misinterpreted by faculty as indication of a desire for economic gain. What is clear, however, is that qualitative data suggest that setting a goal or expectation (i.e., upper panel of "Inputs" box in Figure 2) is important in doctorate completion. Future research should explore why students pursue the doctorate (goals), what they expect of the doctorate, and whether the type of goal or expectation is associated with TTD.

\section{Personal Factors Overweigh Institutional Factors}

An interesting finding is that, whereas students cited various institutional factors as influencing TTD, overall they concurred with the faculty that personal factors (motivation) influenced TTD the most. In contrast, except for GPA at admission, in the quantitative phase, characteristics specific to a student such as gender, race/ethnicity, age at admission, and GRE verbal or quantitative scores were not statistically significantly associated with the timing of doctorate attainment. One explanation for this divergent finding might be that the quantitative phase was limited to only variables that were present in the secondary data. Although we give more weight to the qualitative findings that favor personal factors, it disagrees with Lovitts's (2001) finding that institutional factors exert more influence on persistence than do student characteristics. Although we conceptualize TTD as being influenced by the level of integration in four domains (see 'process' element in Figure 2), findings from both phases suggest that academic integration (followed by social integration) is of paramount importance. 


\section{Academic Integration: Coursework and Dissertation Re- Structuring}

The overwhelming finding that the nature and arrangement of program tasks and resources is associated with TTD might lead departments experiencing longer TTDs to undertake certain structural changes to increase the odds of timely completion. Such changes might include ensuring that faculty members are available to teach courses as scheduled, courses are logically sequenced, the instruction is offered in multiple modes and flexible schedules that accommodate varying students' needs, and research activities and practical application of materials learned in coursework are incorporated. However, the quantitative findings that size of the department housing the program and the proportion of female students in the program are associated with the timing of doctorate attainment might affect the extent to which program structure is related to TTD. For instance, faculty members might be available to teach courses as scheduled; however, they might not be able to serve students adequately in larger departments.

\section{Academic Integration: Emphasis on Research and Writing}

Lovitts (2001), surveying over 800 students, both completers and departers, about their experiences in graduate school and their lives after graduation, established that disappointment with the learning experience contributed to student departure. A consistent finding derived from both phases is that academic preparation plays a pivotal role in TTD. The quantitative results showed that high GPA score at admission (a student-level factor) and high mean GRE quantitative score (a program/institutional level factor) are associated with higher odds of doctorate attainment. Thus, certain academic factors seem to be related to TTD both at student and at program (institution) level. Similarly, qualitative data suggest that research and writing (academic preparation) is important. Although short TTD programs in this college tend to offer students opportunities to participate in various research projects, in most long TTD programs, the first exposure to actual research is when students conduct the dissertation! Thus, we recommend that student engagement in research be formalized and undertaken early in the program. Early exposure, such as attending other dissertation defenses and being part of a research group, affords students the opportunity to practice and hone skills necessary to undertake successfully the dissertation. Engaging in practical hands-on research activities also helps dispel the students' anxiety and negativity towards research. Help with writing should be an integral function of the support center established by the college to help doctoral students with dissertation-related issues.

\section{Academic Integration: Student Enrollment Status}

The perception among faculty members that fulltime enrollment is strongly associated with timely completion is not surprising (Bowen \& Rudenstine, 1992). Thus, administrators may be prompted to formalize fulltime enrollment perhaps including during summer semesters; yet, this effort might be beneficial only in the coursework phase. Students in the ABD stage, the period marking the longest time, might not differ in their enrollment status.

\section{Social Integration: Advising Dynamics}

The lack of information to students about the nature of doctoral study and how to navigate the system successfully (e.g., "cognitive maps"), Lovitts (2001) noted, make students fail to become integrated and depart doctoral study. Student advising is an important aspect of this communication of the information to students. The qualitative phase uncovered interesting findings relating advising to TTD. First, students view advising broadly and expect advice from assigned advisors as well as from other faculty members with whom they interact prior to and during the dissertation stage. Second, faculty members acknowledge that their attitudes toward advisees and the value they attach to advising is pivotal for students' progress. Among the recommendations they 
cited include establishing collegial relationships with advisees, finding out what problems they encounter, helping them define reasonable goals and prodding them to attain the goals, and generally creating an atmosphere where students feel safe to discuss issues that affect their progress. Third, both students and faculty members value timeliness of feedback, a finding that suggests that student progress might increase if faculty members make efforts to provide quality and timely feedback and insist on receiving the same from advisees. These recommendations are consistent with Lovitts' (2001) finding that unsatisfactory advisor relationship is one of the reasons students fail to become integrated into the department and leave. The quantitative finding that the proportion of female students in a program is related to the timing of the doctorate raises questions as to how same-gender or opposite-gender advisor-advisee pairings relate to TTD. Future researchers might explore if there are standard procedures regarding how advising should be conducted, how advisors should be selected or matched with advisees, and whether the student or the advisor should initiate the relationship. Answers to these questions should provide valuable information regarding the relationship between advising and TTD.

\section{Social Integration: Nature of Dissertation Topic Chosen}

Apart from beginning working on the topic early, qualitative findings suggested the following strategies that might increase the odds of timely completion: choosing a topic about which one is passionate, of which one has ownership, that allows one to solve a problem or to learn something of interest, and in which one's committee has expertise. Although researchers have examined the relationship of the dissertation topic and persistence, little is known about how the candidates identify the topic, whether it matters if it originates from a faculty member's research agenda or from the student, the extent that students perceive they have ownership over the topic, and the extent that the changes suggested by the dissertation committee alter students' interest, motivation, and passion for the topic. These are ripe topics for future inquiry in an attempt to delve into the nature of a successful dissertation topic.

\section{Conclusion}

Time taken to complete the doctorate (TTD) is important to students, educators, employers, and other stakeholders. Results of this sequential quantitative-qualitative mixed research study reveal that factors related to TTD are intertwined and involve a complex interplay of institutional and personal factors. Academic integration factors, in particular, how the program is structured, levels of academic preparation, and whether a student is enrolled full-time versus part-time, have the strongest influence on TTD. This is followed by social integration factors, particularly the nature of advising and of dissertation topic chosen by students wherein the influence of economic factors (e.g., work and financial support) is moderate. Personal attributes (e.g., the level of motivation) and external factors (e.g., family obligations) also have some association with TTD. In sum, the level of integration in one or more of these domains of integration (i.e., academic, social, economic, personal, and external factors) influences how one progresses in the path to doctorate completion. The more integrated a student is, the higher the likelihood that the student will complete the doctorate in a timely fashion.

\section{Limitations}

The quantitative phase was limited to variables that were available from the secondary data source. Studying only a subset of the variables limits the conclusions that can be drawn. Having only variables whose values remain constant throughout the observation period was a potential threat to the temporal validity of the findings. Although data from student interviews and faculty focus groups appeared to reach data saturation, part of the data (from graduates and faculty) was dependent on participants' accurate recall of information. Extrapolating findings to doctoral stu- 
dents in other colleges is uncertain because this study was limited to a single institution; however, to the extent that characteristics of the various doctoral programs in other colleges match those examined here, the findings might be useful in identifying factors associated with TTD in similar colleges (case-to-case transfer; Yin, 2009). As suggested by Onwuegbuzie, Slate, Leech, and Collins (2009), we encourage readers (i.e., doctoral students and faculty members) to identify aspects of this study that apply to their contexts and assess the extent to which they can make naturalistic generalizations.

\section{References}

Allison, P. D. (2001). Event history analysis: Regression for longitudinal event data. Newbury Park, CA: Sage.

Bair, C. R. (1999). Doctoral student's attrition and persistence. A meta-analysis of research. Ph.D. dissertation, Loyola University Chicago, United States-Illinois, Retrieved February 14, 2009, from ProQuest Digital Dissertations database. (Publication No. AAT 9917754).

Bauer, E. R. (2004). An examination of the effect of departmental factors on student completion of doctoral requirements. Doctoral dissertation, University of Massachusetts, United States-Massachusetts, Retrieved from ProQuest Digital Dissertations database. (Publication No. AAT 3133568).

Boyle, P., \& Boice, B. (1998). Best practices for enculturation: Collegiality, mentoring, and structure. New Directions for Higher Education, 101, 87-94. doi:10.1002/he.10108

Bowen, G. W., \& Rudenstine, N. L. (1992). In pursuit of the Ph.D. Princeton, NJ: Princeton University Press.

The Carnegie Foundation for the Advancement of Teaching. (n.d). The Carnegie Classification of Institutions of Higher Education. Retrieved from http://www.carnegiefoundation.org/classifications

Civian, J. T. (1990). Using proportional hazards models to examine time to doctorate. Unpublished doctoral dissertation, Harvard University, Massachusetts.

Creswell, J. (2007). Qualitative inquiry and research design: Choosing among five traditions (2nd ed.) Thousand Oaks: Sage.

Denzin, N. K. (1978). The research act: A theoretical introduction to sociological methods. New York, NY: Praeger.

Dinham, S., \& Scott, C. (1999). The doctorate: Talking about the degree. University of Western Sydney. Nepean: Kingswood NSW, Australia. (ERIC Document Reproduction Service No. ED435305)

Ferrer de Valero, Y. F. (2001). Departmental factors affecting time-to-degree and completion rates of doctoral students at one land-grant research institution. The Journal of Higher Education, 72, 341-367.

Geertz, C. (1973). Thick description toward an interpretive theory of culture. In C. Geertz (Ed.), The interpretation of cultures (pp. 3-30). New York, NY: Basic Books.

Girves, J. E., \& Wemmerus, V. (1988). Developing models of graduate degree progress. The Journal of Higher Education, 59, 163-189. doi:10.2307/1981691

Golde, C. M. (2000). Should I stay or should I go? Students' descriptions of the doctoral attrition process. The Review of Higher Education, 23, 199-227.

Greene, J. C., Caracelli, V. J., \& Graham, W. F. (1989). Toward a conceptual framework for mixed-method evaluation designs. Educational Evaluation and Policy Analysis, 11, 255-274. doi:10.2307/1163620

Hoffer, T. B., Hess, M. D., Welch, V., \& Williams, K. (2007). Doctorate recipients from United States universities: Summary report 2006. Chicago, IL: National Opinion Research Center. (The report gives the results of data collected in the Survey of Earned Doctorates, conducted by NORC for six federal agencies: NSF, NIH, USED, NEH, USDA, and NASA.). 
Jiranek, V. (2010). Potential predictors of timely completion among dissertation research students at an Australian faculty of science. International journal of Doctoral Studies, 5, 1-13.

Johnson, R. B. (2009). Comment on Howe: Toward a more inclusive "Scientific Research in Education." Educational Researcher 38, 449-457. doi: 10.3102/0013189X09344429

Leech, N. L., \& Onwuegbuzie, A. J. (2009). A typology of mixed methods research designs. Quality \& Quantity: International Journal of Methodology, 43, 265-275. doi:10.1007/s11135-007-9105-3

Lincoln, Y. S. \& Guba, E. G. (1985). Naturalistic inquiry. Beverly Hills, CA: Sage.

Lovitts, B. E. (2001). Leaving the Ivory Tower: The causes and consequences of departure from doctoral study. Lanham, MD: Rowman \& Littlefield.

Maher, M. A., Ford, M. E., \& Thompson, C. M. (2004). Degree progress of women doctoral students: Factors that constrain, facilitate, and differentiate. The Review of Higher Education, 27, 385-408. doi:10.1353/rhe.2004.0003

Maxwell, J. A. (1992). Understanding and validity in qualitative research. Harvard Educational Review, 62, 279-299.

McFarland, R. T., \& Caplow, J. H. (1995, November). Faculty perspectives of doctoral persistence within arts and science disciplines. Paper presented at the annual meeting of the Association for the Study of Higher Education, Orlando, FL.

Miles, M. B., \& Huberman, A. M. (1994). Qualitative data analysis: A sourcebook of new methods. Beverly Hills, CA: Sage.

Moustakas, C. (1994). Phenomenological research methods. Thousand Oaks, CA: Sage.

Nerad, M., \& Cerny, J. (1993). From facts to action: Expanding the graduate division's educational role. New Directions for Institutional Research, 80, 27-40. doi:10.1002/ir.37019938005

Onwuegbuzie, A. J. (2003). Effect sizes in qualitative research: A prolegomenon. Quality \& Quantity: International Journal of Methodology, 37, 393-409.

Onwuegbuzie, A. J., \& Johnson, B. (2006). The validity issues in mixed research. Research in Schools, 13(1), 48-63.

Onwuegbuzie, A. J., Johnson, R. B., \& Collins, K. M. T. (2009). A call for mixed analysis: A philosophical framework for combining qualitative and quantitative. International Journal of Multiple Research Approaches, 3, 114-139.

Onwuegbuzie, A. J., Slate, J. R., Leech, N. L., \& Collins, K. M. T. (2009). Mixed data analysis: Advanced integration techniques. International Journal of Multiple Research Approaches, 3, 13-33.

Onwuegbuzie, A. J., \& Teddlie, C. (2003). A framework for analyzing data in mixed methods. In A. Tashakkori \& C. Teddlie (Eds.), Handbook of mixed methods in social and behavioral research (pp. 351383). Thousand Oaks, CA: Sage.

Raudenbush, S. W., \& Bryk, A. S. (2002). Hierarchical linear models: Applications and data analysis methods (2nd ed.). Thousand Oaks, CA: Sage.

SAS Institute Inc. (2009). SAS Online Documentation (Version 8) [Computer software]. Cary, NC: SAS Institute Inc.

Schwandt, T. A. (2007). The sage dictionary of qualitative inquiry (3rd ed.). Thousand Oaks, CA: Sage.

Stiles, J. E. M. (2003). The hazard of success: A longitudinal study of time-to-degree among doctoral students using discrete-time survival analysis. ProQuest Digital Dissertations (UMI No. 3100170).

Stolzenberg, E. B. (2006). The dynamics of the doctoral student-faculty advising relationship: A study across academic fields. Doctoral dissertation, University of California, United States-California, Retrieved from ProQuest Digital Dissertations database. (Publication No. AAT 3240946). 
Strayhorn, T. L. (2005). More than money matters: An integrated model of graduate student persistence. Unpublished doctoral dissertation, Virginia Tech, Virginia.

Tinto, V. (1993). Leaving college: Rethinking the causes and cures of student attrition (2nd ed.). Chicago, IL: The University of Chicago Press.

Tuckman, H., Coyle, S., \& Bae, B. (1990). On time to the doctorate. Washington, D. C.: National Academies Press

Wao, H. O. (2010). Time to the doctorate: Multilevel discrete-time hazard analysis. Educational Assessment Evaluation and Accountability, 22, 227-247.

Yin, R. K. (2009). Case study research: Design and methods (4th ed.). Thousand Oaks, CA: Sage.

\section{Biographies}

Hesborn Wao is an assistant professor in the Division of Evidence-Based Medicine and Health

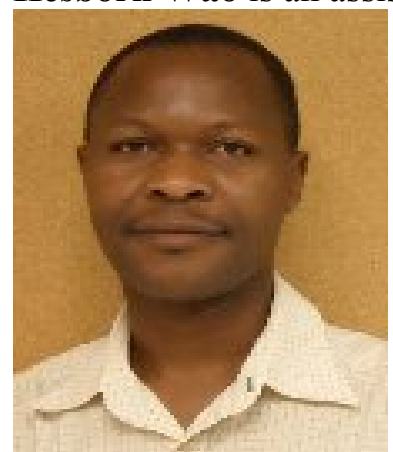
Outcomes Research, University of South Florida. His research interests include the effects of social organizations on student outcomes, with interests including application of mixed methods approaches to research/evaluation design, systematic review and meta-analysis, and secondary data analysis. His recent works have appeared in Educational Assessment, Evaluation and Accountability; Journal of the Scholarship of Teaching and Learning; Journal of Women and Minorities in Science and Engineering, Quality \& Quantity: International Journal of Methodology, including two book chapters in Becoming an engineer in public universities: Pathways for women and minorities.

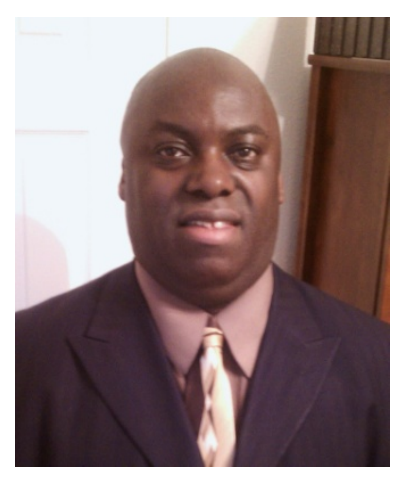

Anthony Onwuegbuzie is a tenured professor in the Department of Educational Leadership and Counseling at Sam Houston State University. He teaches doctoral-level courses in qualitative research, quantitative research, and mixed research. His research areas include disadvantaged and under-served populations such as minorities, juvenile delinquents, and children living in war zones. Additionally, he writes extensively on qualitative, quantitative, and mixed methodological topics. Alongside more than 600 conference/keynote presentations, he has had published more than 300 works, including more than 255 journal articles, 50 book chapters, and 2 books. His current h-index is 38 . He serves as co-editor of Research in the Schools. 